\title{
Measuring selective effects of modifier gene polymorphisms on the Bare locus of Drosophila subobscura
}

\author{
GONZALO ALVAREZ* \& CARLOS ZAPATA \\ Departamento de Biología Fundamental, Facultad de Biología, Universidad de Santiago de Compostela, \\ Santiago de Compostela, Spain
}

\begin{abstract}
An attempt to quantify the effects of modifier gene polymorphisms on the operation of natural selection on a major locus has been carried out. The modifier system we have investigated is constituted by a set of polygenic modifier loci affecting the morphological expression of the Bare $(B a)$ bristle mutant of Drosophila subobscura. $B a$ is a dominant mutant that is lethal in homozygous condition and both the polygenic modifiers and $B a$ are located on the O chromosome of this species. Experimental populations were founded with $\mathrm{Ba} /+$ individuals and two different types of populations were started according to their modifier genetic background: populations with wild $\mathrm{O}$ chromosomes of either high or low modifier effect (cages $\mathrm{H}$ and $\mathrm{L}$, respectively). Fitness estimates (total fitness, viability and fertility) for genotypes of the $B a$ locus were obtained under the two different modifier backgrounds. In the populations with high modifier background the total fitness of the $B a /+$ heterozygote was very similar to that of the $+/+$ homozygote (fitness equal to 1 ). However, in cages with low modifier background a strong selection against the $\mathrm{Ba} /+$ heterozygote was detected (average of total fitnesses over generations was $0.66 \pm 0.10$ ), and fertility appears to be the fitness component responsible for this effect (mean fertility was $0.55 \pm 0.08$ ). These findings demonstrate that modifier gene polymorphisms affecting the expression of the $B a$ mutant may be associated with large selective effects on the major locus.
\end{abstract}

Keywords: Drosophila subobscura, fitness estimation, modifier gene polymorphisms.

\section{Introduction}

It has been suggested that modifier gene polymorphisms may provide an important source of variation for adaptive evolutionary change (McDonald \& Ayala, 1978a,b; Laurie-Ahlberg et al., 1982; Templeton, 1982; Geer \& Laurie-Ahlberg, 1984; LaurieAhlberg, 1985). In fact, experimental evidence shows that high levels of modifier genetic variability frequently occur in natural populations of species such as Drosophila. Thus, polygenic modifiers affecting the phenotypic expression of morphological mutants (major loci) have been detected in many natural populations (Milkman, 1970; Thoday \& Thompson, 1984; Thompson \& Spivey, 1984; Alvarez et al., 1990). At the biochemical level, naturally occurring genetic variation of specific

\footnotetext{
*Correspondence.
}

enzyme activities caused by activity modifiers has been reported for a large number of enzymes coded by structural loci (see Laurie-Ahlberg, 1985, for a review). However, the adaptive significance of modifier gene polymorphisms remains largely undetermined because, to date, the selective effects of modifier loci on the structural or major locus have not been measured either for modifiers of enzyme activity or modifiers of morphological mutants.

The main goal of this paper is to quantify the selective effects of a set of polygenic modifier loci affecting the morphological expression of the Bare $(B a)$ mutant of $D$. subobscura. Bare is a dominant mutant located on the $\mathrm{O}$ chromosome (map position $54.7 \mathrm{cM}$ ) of this species that reduces variably the number of bristles of the fly and is lethal in homozygous condition (Koske \& Maynard Smith, 1954; Sperlich et al., 1977; Loukas et al., 1979). It has been demonstrated that $\mathrm{O}$ chromosomes derived from 
natural populations show considerable genetic variation in modifier effect upon $B a$ expression (Alvarez et al., 1980, 1990). The analysis of the genetic architecture of this modifier variability carried out using biometrical techniques for locating and mapping polygenes showed that the differences in modifier effect between a wild $\mathrm{O}$ chromosome of high modifier effect and a marker chromosome of low score can be explained by a relatively small number of polygenic modifier factors (Alvarez et al., 1981, 1990). In addition, these modifier factors show a nonuniform distribution along the $\mathrm{O}$ chromosome and some indication of clustering around the major locus (Ba) (Alvarez et al., 1981, 1990). This particular genetic architecture suggests that the $B a$ locus together with the modifiers probably constitute a coadapted gene complex in such a way that this multilocus complex could be surely considered as a unit of selection.

In the present work, experimental populations (population cages) were founded with $\mathrm{Ba} /+$ individuals and two different types of populations with respect to the modifier genetic background of the $\mathrm{O}$ chromosome were started: populations with wild $\mathrm{O}$ chromosomes of either high or low modifier effect. Changes in the $\mathrm{Ba} /+$ frequency along generations were recorded in both types of experimental populations and were used to obtain fitness estimates to characterize the operation of natural selection on the $B a$ mutant under the two different modifier genetic backgrounds. The results obtained in the present work show that the polygenic modifier factors located on the $\mathrm{O}$ chromosome of $D$. subobscura affecting the expression of $B a$ mutant are producing very large selective effects on the major locus.

\section{Materials and methods}

\section{Isogenic lines}

A large number of $\mathrm{O}$ chromosomes were extracted from wild males caught in the natural population of El Pedroso (Santiago de Compostela, NW of Spain) by means of crosses with the chu-chu and $\mathrm{Va} / \mathrm{Ba}$ strains according to the experimental design described by Zapata et al. (1986). The $V a / B a$ stock is a balanced lethal strain for the $\mathrm{O}$ chromosome of $D$. subobscura, where $\mathrm{Va}$ (Varicose, wing venation mutant) and $\mathrm{Ba}$ (Bare) are two dominant morphological mutants, both lethal in homozygous condition (Koske \& Maynard Smith, 1954; Sperlich et al., 1977; Böhm et al., 1987). The Ba chromosome of the $\mathrm{Va} / \mathrm{Ba}$ strain carried the $\mathrm{O}_{\mathrm{ST}}$ chromosomal arrangement. The chromosomal arrangement of each one of the wild $\mathrm{O}$ chromosomes was identified by observation of polytene chromosomes. The modifier effect of these wild $\mathrm{O}$ chromosomes on the phenotypic expression of the Bare mutant caused by modifier polygenes located on the $\mathrm{O}$ chromosome was also evaluated by measuring the difference in mean number of bristles between $B a /+$ and $V a / B a$ individuals (see Alvarez et al., 1990). Twelve bristles per individual (four scutellars, four dorsocentrals, two supra-alars and two postalars) of $30 \mathrm{Ba} /+$ and 30 $\mathrm{Va} / \mathrm{Ba}$ flies were scored in each one of three to four replicates to estimate the modifier effect of each chromosome. Moreover, the viability of the wild $\mathrm{O}$ chromosomes relative to the $V a / B a$ genotype was estimated. In this way, at the end of the isogenization procedure several isogenic lines for the $\mathrm{O}$ chromosome with the $\mathrm{O}_{\mathrm{ST}}$ chromosomal arrangement and extreme modifier scores were obtained (Table 1).

Table 1 Modifier effect (measured as the difference in mean number of bristles between $B a /+$ and $V a / B a$ controls) and relative viability of the $\mathrm{O}$ chromosomes used for founding the experimental populations of Drosophila subobscura

\begin{tabular}{|c|c|c|c|c|c|}
\hline \multicolumn{3}{|c|}{$\mathrm{H}$ populations } & \multicolumn{3}{|c|}{$\mathrm{L}$ populations } \\
\hline Isogenic line & Modifier effect \pm SE & Relative viability & Isogenic line & Modifier effect $\pm S E$ & Relative viability \\
\hline 456 & $5.0 \pm 0.4$ & 0.59 & $69-\mathrm{L}$ & $-0.7 \pm 0.5$ & 1.15 \\
\hline 527 & $6.1 \pm 0.2$ & 0.57 & $166-\mathrm{L}$ & $1.1 \pm 0.3$ & 1.03 \\
\hline $199-\mathrm{L}$ & $5.5 \pm 0.1$ & 0.95 & $351-\mathrm{L}$ & $-0.5 \pm 0.2$ & 1.20 \\
\hline $221-\mathrm{L}$ & $5.8 \pm 0.03$ & 0.83 & $360-\mathrm{L}$ & $-0.5 \pm 0.1$ & 0.32 \\
\hline $290-\mathrm{L}$ & $6.3 \pm 0.4$ & 1.03 & $363-\mathrm{L}$ & $-1.2 \pm 0.2$ & 1.22 \\
\hline $353-\mathrm{L}$ & $5.9 \pm 0.2$ & 0.99 & & & \\
\hline Mean \pm SE & $5.8 \pm 0.2$ & $0.83 \pm 0.08$ & Mean \pm SE & $-0.3 \pm 0.4$ & $0.98 \pm 0.17$ \\
\hline
\end{tabular}

(c) The Genetical Society of Great Britain, Heredity, 76, 404-411. 


\section{Experimental populations}

To start laboratory population cages with $\mathrm{Ba} /+$ individuals bearing $\mathrm{O}$ chromosomes of either high or low modifier effect 15 males from each isogenic line were individually crossed with five $V a / B a$ virgin females. Sixty $\mathrm{Ba} /+$ males and $60 \mathrm{Ba} /+$ virgin females from the offspring of each one of the six isogenic lines of high modifier effect were used to start a population cage with $360 \mathrm{Ba} /+$ males and $360 \mathrm{Ba} /+$ virgin females. Similarly, $70 \mathrm{Ba} /+$ males and $70 \mathrm{Ba} /+$ virgin females of each one of the five isogenic lines of low modifier effect were used to initiate a population cage with $350 \mathrm{Ba} /+$ males and $350 \mathrm{Ba} /+$ virgin females. In this way, two population cages denoted by $\mathrm{H}$ (high modifier effect) and $\mathrm{L}$ (low modifier effect), respectively, were founded. Each one of these two population cages was initiated with 14 cups with culture medium. Before adult individuals corresponding to the first generation had eclosed from the cages two sets of seven random cups from each cage were used to obtain two replicate populations for each one of the original cages: $\mathrm{H}_{1}$ and $\mathrm{H}_{2}$, and $\mathrm{L}_{1}$ and $\mathrm{L}_{2}$.

The populations were sampled regularly by taking eggs and adults from the cages. Eggs were sampled by introducing three cups with fresh medium for $24 \mathrm{~h}$ in each cage. The sampling of adults was carried out by removing three cups from each cage. The modifier effect of $\mathrm{O}$ chromosomes extracted from the experimental populations was measured for all generations of the experiment. In each generation, 15 wild males from each one of the four cages were individually crossed to five $\mathrm{Va} / \mathrm{Ba}$ virgin females and one $\mathrm{Va} /+$ male of the offspring was mated to five $V a / B a$ virgin females. The difference in mean number of bristles between $30 \mathrm{Ba} /+$ and $30 \mathrm{Va} / \mathrm{Ba}$ individuals of the offspring of the last cross was used as a measure of the modifier effect of the $O$ chromosome.

\section{Statistical analysis}

Population genotype frequencies in consecutive generations have been used to obtain reliable fitness estimates (Prout, 1969; Alvarez et al., 1984). If genotypic frequencies are denoted by $f_{i j}(i=1,2,3$ and $j=1,2$ ), being $i=1, i=2$ and $i=3$ zygotes at generation $t$, adults at $t$ and zygotes at $t+1$, respectively, and $j=1$ and $j=2 B a /+$ and $+/+$ genotypes, respectively, the estimates of viability $(\hat{V})$, fertility $(\hat{F})$ and total fitness $(\hat{W})$ of the $B a /+$ heterozygote relative tothe $+/+$ genotype (fitness equal to 1 ) are: $\hat{V}=\left(f_{21} f_{12}\right) /\left(f_{22} f_{11}\right), \hat{F}=\left[2 f_{31}\left(1-f_{21}\right)\right] /\left[\left(2-3 f_{31}\right) f_{21}\right]$ and $\quad \hat{W}=\left[2 f_{31}\left(1-f_{11}\right)\right] /\left[\left(2-3 f_{31}\right) f_{11}\right], \quad$ assuming random mating and sex-independent selection (Anderson, 1969; Polivanov \& Anderson, 1969; Sved $\&$ Ayala, 1970). These are maximum likelihood estimates and Polivanov \& Anderson (1969) have obtained their asymptotic sampling variances for large samples when all the adults of the population are counted. In the general case, when a sample of the adult population is taken, the sampling variances of the fitness estimates are not available. However, these variances can be evaluated as the variances of a product of ratios taking into account that the two genotype samples involved in each fitness estimate (for example, zygotes and adults at $t$ for viability) can be considered independent (see Connolly \& Gliddon, 1984). Then, the problem reduces to an evaluation of the variances of the ratios of terms of a binomial distribution which can be easily approximated by use of the Taylor's series expansion. In large samples, the asymptotic sampling variances of viability, fertility and total fitness for the heterozygote at an autosomal locus, lethal in homozygous condition, are approximately

$$
\begin{aligned}
\operatorname{Var}(\hat{V})= & \frac{\hat{V}\left(1+f_{11} f_{12} N_{1}+f_{21} f_{22} N_{2}\right)}{N_{1} N_{2} f_{11}^{2} f_{22}^{2}}, \\
\operatorname{Var}(\hat{F})= & {\left[\frac{2 \hat{F}}{\left(2-3 f_{31}\right) f_{21}}\right]\left[\frac{4 f_{32}}{\left(2-3 f_{31}\right)^{2} f_{21} N_{2} N_{3}}\right.} \\
& \left.+\frac{4 f_{32} f_{22}}{\left(2-3 f_{31}\right)^{2} N_{3}}+\frac{f_{31}}{f_{21} N_{2}}\right] \text { and } \\
\operatorname{Var}(\hat{W})= & {\left[\frac{2 \hat{W}}{\left(2-3 f_{31}\right) f_{11}}\right]\left[\frac{4 f_{32}}{\left(2-3 f_{31}\right)^{2} f_{11} N_{1} N_{3}}\right.} \\
& \left.+\frac{4 f_{32} f_{12}}{\left(2-3 f_{31}\right)^{2} N_{3}}+\frac{f_{31}}{f_{11} N_{1}}\right]
\end{aligned}
$$

where $N_{1}, N_{2}$ and $N_{3}$ are the numbers of zygotes at $t$, adults at $t$ and zygotes at $t+1$, respectively. Selective differences between the $\mathrm{Ba} /+$ and $+/+$ genotypes for viability, fertility and total fitness can be evaluated by means of approximate significance tests given that the fitness estimates are maximum likelihood estimates and, therefore, they are approximately normally distributed. So, for total selection, for example, $Z^{2}=(\hat{W}-1)^{2} / \operatorname{Var}(\hat{W})$ is approximately distributed as $\chi^{2}$ with 1 d.f. when $W=1$, and in this way the null hypothesis of no selection $(W=1)$ can be tested. Similar tests can be performed for the partial finess components.

(C) The Genetical Society of Great Britain, Heredity, 76, 404-411. 


\section{Results}

Four experimental populations were founded with $\mathrm{Ba} /+$ individuals that are heterozygotes between wild $\mathrm{O}$ chromosomes and $\mathrm{Ba}$ chromosomes of the $\mathrm{Va} / \mathrm{Ba}$ strain. Cages $\mathrm{H}$ were founded with wild $\mathrm{O}$ chromosomes of high modifier effect and cages $\mathrm{L}$ with $\mathrm{O}$ chromosomes of low modifier effect (differences in mean number of bristles between $\mathrm{Ba} /+$ individuals and $\mathrm{Va} / \mathrm{Ba}$ controls were $5.8 \pm 0.2 \mathrm{SE}$ for the chromosomes of the $\mathrm{H}$ cages and $-0.3 \pm 0.4$ for the chromosomes of the L cages; Table 1). This important difference in modifier effect between cages $\mathrm{H}$ and $\mathrm{L}$ is maintained in all generations of the experiment and, thus, the averages over generations of the modifier effect of $\mathrm{O}$ chromosomes extracted from the cages were $5.8 \pm 0.1$ and $5.9 \pm 0.1$ in cages $\mathrm{H}_{1}$ and $\mathrm{H}_{2}$, respectively, and $1.2 \pm 0.1$ and $1.1 \pm 0.1$ in cages $L_{1}$ and $L_{2}$, respectively.

The frequencies of the $\mathrm{Ba} /+$ genotype in adults hatching from egg samples (zygotic frequencies) and in adults at the time of reproduction (adult frequencies) in each generation in the $\mathrm{H}$ and $\mathrm{L}$ experimental populations were recorded. Mean sample sizes for adults hatching from egg samples range from $527.2 \pm 27.1$ (cage $\mathrm{H}_{1}$ ) to $568.4 \pm 28.6$ (cage $\mathrm{H}_{2}$ ), and mean sample sizes for adults at reproduction range from $259.2 \pm 12.8$ (cage $\mathrm{H}_{2}$ ) to $281.6 \pm 19.4$ (cage $\mathrm{H}_{1}$ ). The zygotic frequencies of the $B \bar{a} /+$ heterozygote in the four population cages are graphed in Fig. 1. In accordance with the operation of natural selection on an autosomal lethal gene there is a strong decline of $B a /+$ frequency with time in both $\mathrm{H}$ and $\mathrm{L}$ cages. The change of $\mathrm{Ba} /+$ frequency is clearly more abrupt in cages $\mathbf{L}$ than in cages $\mathrm{H}$ suggesting a stronger operation of natural selection on the $B a /+$ heterozygote in $\mathrm{L}$ populations. A certain divergence for the $\mathrm{Ba} /+$ frequency is observed in the two cages $\mathrm{H}$, especially from generation 8 . On the contrary, the pattern of change of the $\mathrm{Ba} /+$ frequency is very similar in the two cages $\mathrm{L}$. The difference between the $\mathrm{H}$ and $\mathrm{L}$ populations in the rate of elimination of the $B a$ allele could be the result of, at least partially, fitness effects at loci in gametic disequilibrium with the $B a$ locus, which are independent of the genes that affect bristle number. Gametic disequilibrium between the $B a$ locus and linked loci could be generated by founder effect given the relatively low number of independently derived chromosomes used to start the populations. However, it must be considered that the wild chromosomes of high and low modifier effect used in the foundation of the experimental populations were very similar in fitness, at least for

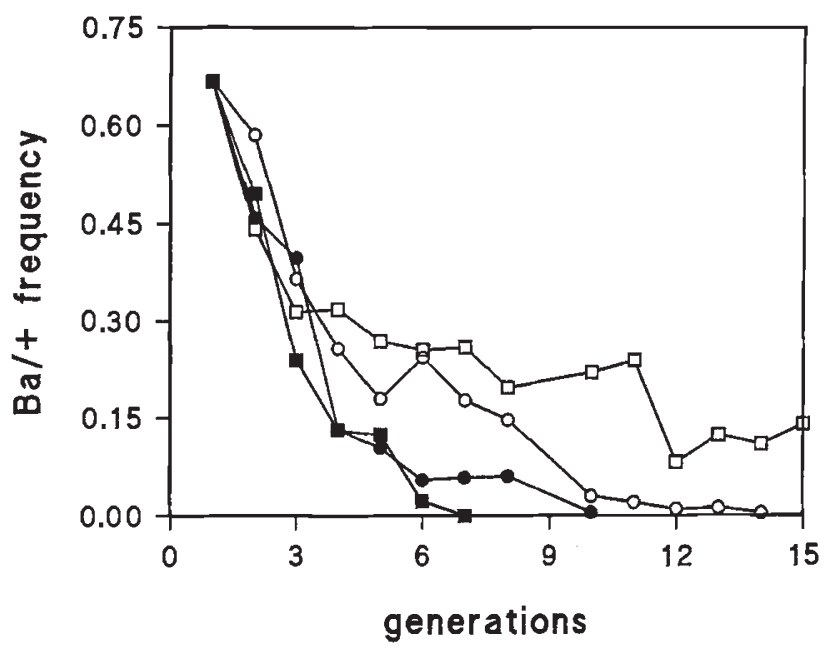

Fig. 1 Frequency of the $B a /+$ heterozygote in egg samples from the four experimental populations of Drosophila subobscura $\left(\mathrm{H}_{1}\right.$ : open circles; $\mathrm{H}_{2}$ : open squares; $\mathrm{L}_{1}$ : solid circles; $\mathrm{L}_{2}$ : solid squares).

the viability component $(0.83 \pm 0.08$ and $0.98 \pm 0.17$ for $\mathrm{H}$ and $\mathrm{L}$ chromosomes, respectively, $t_{9}=-0.88$, $P>0.05$; Table 1 ).

Estimates of egg-to-adult viability, fertility and total fitness of the $B a /+$ heterozygote relative to the $+/+$ genotype (fitness equal to 1 ) were obtained in each generation in cages $\mathrm{H}$ and $\mathrm{L}$ (Tables 2 and 3 ). For fitness estimation the zygotic frequency of $\mathrm{Ba} /+$ heterozygotes was corrected as this frequency is estimated at the adult stage rather than the egg stage (see Sved, 1971). The null hypothesis of no selective differences between $\mathrm{Ba} /+$ and $+/+$ genotypes was tested by means of two different statistical approaches: an approximate significance test based on the $\chi^{2}$ distribution (see Materials and methods) and the 95 per cent bootstrap confidence intervals (Efron \& Tibshirani, 1986). In 88 of a total of 90 cases ( 97.8 per cent) the $\chi^{2}$-test and the bootstrap interval gave the same result and in only two cases was statistical significance obtained by the $\chi^{2}$-test but not by the bootstrap interval. Therefore, these two different statistical approaches give very similar results for which only the $\chi^{2}$-tests are given in Tables 2 and 3 . With respect to total fitness estimates, only seven of 17 values are statistically significant in cages $\mathrm{H}$, and five of these values are less than one whereas two are more than one. In cages L, five of ten estimates are statistically significant and all these estimates are less than one. Therefore, a selective effect against the $\mathrm{Ba} /+$ heterozygote for total fitness appears to be present in cages $\mathrm{L}$. This selective effect seems to be associated with the fertility component of the total fitness, because in cages $\mathrm{L}$ 
Table 2 Fitness estimates for the $B a /+$ heterozygotes in $\mathrm{H}$ (high modifier effect) populations of Drosophila subobscura

\begin{tabular}{|c|c|c|c|c|c|c|}
\hline \multirow[b]{2}{*}{ Generation } & \multicolumn{2}{|c|}{ Viability } & \multicolumn{2}{|c|}{ Fertility } & \multicolumn{2}{|c|}{ Total fitness } \\
\hline & $\hat{V} \pm \mathrm{SE} \dagger$ & $\chi^{2}$ & $\hat{F} \pm \mathrm{SE} \dagger$ & $\chi^{2}$ & $\hat{W} \pm \mathrm{SE} \dagger$ & $\chi^{2}$ \\
\hline \multicolumn{7}{|c|}{$\mathrm{H}_{1}$ population } \\
\hline 1 & 1.18 & & $1.06 \pm 0.28$ & 0.05 & 1.24 & \\
\hline 2 & $0.84 \pm 0.13$ & 1.27 & $0.62 \pm 0.11$ & $7.40^{* *}$ & $0.53 \pm 0.07$ & $23.89^{* *}$ \\
\hline 3 & $0.87 \pm 0.12$ & 1.02 & $0.80 \pm 0.13$ & 1.89 & $0.70 \pm 0.10$ & $6.30^{*}$ \\
\hline 4 & $1.51 \pm 0.27$ & $5.39^{*}$ & $0.46 \pm 0.09$ & $16.56^{* *}$ & $0.69 \pm 0.12$ & $4.61^{*}$ \\
\hline 5 & $0.94 \pm 0.19$ & 0.09 & $1.81 \pm 0.36$ & $9.16^{* *}$ & $1.70 \pm 0.31$ & $8.67^{* *}$ \\
\hline 6 & $0.81 \pm 0.15$ & 1.30 & $0.91 \pm 0.19$ & 0.20 & $0.73 \pm 0.14$ & 2.72 \\
\hline 7 & $0.37 \pm 0.11$ & $12.14^{* *}$ & $2.30 \pm 0.73$ & $7.29 * *$ & $0.85 \pm 0.20$ & 0.48 \\
\hline 8 & $0.34 \pm 0.12$ & $10.29^{* *}$ & & & & \\
\hline \multicolumn{7}{|c|}{$\mathrm{H}_{2}$ population } \\
\hline 1 & 1.19 & & $0.38 \pm 0.07$ & $29.81^{*}$ & 0.45 & \\
\hline 2 & $1.24 \pm 0.19$ & 1.98 & $0.57 \pm 0.10$ & $10.54^{* *}$ & $0.71 \pm 0.09$ & $7.37^{* *}$ \\
\hline 3 & $1.55 \pm 0.25$ & $7.50 * *$ & $0.81 \pm 0.15$ & 1.30 & $1.24 \pm 0.19$ & 1.98 \\
\hline 4 & $1.21 \pm 0.21$ & 1.21 & $0.77 \pm 0.14$ & 2.08 & $0.92 \pm 0.14$ & 0.30 \\
\hline 5 & $1.17 \pm 0.20$ & 0.85 & $0.92 \pm 0.17$ & 0.20 & $1.08 \pm 0.17$ & 0.24 \\
\hline 6 & $0.71 \pm 0.15$ & 2.65 & $1.67 \pm 0.35$ & $6.12^{*}$ & $1.19 \pm 0.19$ & 1.19 \\
\hline 7 & $2.22 \pm 0.35$ & $26.97^{* *}$ & $0.35 \pm 0.08$ & $23.11^{* *}$ & $0.78 \pm 0.16$ & 1.48 \\
\hline 8 & $0.76 \pm 0.22$ & 0.90 & & & & \\
\hline 10 & $1.17 \pm 0.22$ & 0.70 & $1.09 \pm 0.22$ & 0.18 & $1.27 \pm 0.21$ & 2.10 \\
\hline 11 & $1.25 \pm 0.21$ & 1.77 & $0.24 \pm 0.05$ & $55.45^{* *}$ & $0.30 \pm 0.06$ & $40.83^{* *}$ \\
\hline 12 & $2.73 \pm 0.70$ & $16.68 * *$ & $0.60 \pm 0.15$ & $4.27^{*}$ & $1.65 \pm 0.36$ & $5.38^{*}$ \\
\hline 13 & $1.52 \pm 0.32$ & $4.01 *$ & $0.61 \pm 0.13$ & $5.49^{*}$ & $0.92 \pm 0.19$ & 0.16 \\
\hline 14 & $1.42 \pm 0.34$ & 2.17 & $0.99 \pm 0.23$ & 0.002 & $1.41 \pm 0.28$ & 3.02 \\
\hline 15 & $1.00 \pm 0.24$ & 0.00 & & & & \\
\hline
\end{tabular}

$\uparrow$ Asymptotic standard error.

${ }^{*} P<0.05,{ }^{* *} P<0.01$.

Table 3 Fitness estimates for the Bal + heterozygotes in L (low modifier effect) populations of Drosophila subobscura

\begin{tabular}{|c|c|c|c|c|c|c|}
\hline \multirow[b]{2}{*}{ Generation } & \multicolumn{2}{|c|}{ Viability } & \multicolumn{2}{|c|}{ Fertility } & \multicolumn{2}{|c|}{ Total fitness } \\
\hline & $\hat{V} \pm \mathrm{SE} \dagger$ & $\chi^{2}$ & $\hat{F} \pm \mathrm{SE} \dagger$ & $x^{2}$ & $\hat{W} \pm \mathrm{SE} \dagger$ & $\chi^{2}$ \\
\hline \multicolumn{7}{|c|}{$\mathrm{L}_{1}$ population } \\
\hline 1 & 0.81 & & $0.61 \pm 0.10$ & $9.28^{* *}$ & 0.50 & \\
\hline 2 & $1.74 \pm 0.25$ & $15.25^{* *}$ & $0.60 \pm 0.10$ & $9.60^{* *}$ & $1.05 \pm 0.15$ & 0.12 \\
\hline 3 & $0.80 \pm 0.14$ & 1.63 & $0.31 \pm 0.07$ & $30.12^{* *}$ & $0.25 \pm 0.04$ & $87.89^{* *}$ \\
\hline 4 & $1.66 \pm 0.36$ & $5.58^{*}$ & $0.48 \pm 0.11$ & $10.73^{* *}$ & $0.79 \pm 0.17$ & 1.21 \\
\hline 5 & $1.81 \pm 0.45$ & $5.86^{*}$ & $0.28 \pm 0.08$ & $22.68^{* *}$ & $0.51 \pm 0.14$ & $6.25^{*}$ \\
\hline 6 & $0.86 \pm 0.35$ & 0.14 & $1.29 \pm 0.52$ & 0.40 & $1.10 \pm 0.33$ & 0.10 \\
\hline 7 & $1.23 \pm 0.39$ & 0.43 & $0.87 \pm 0.30$ & 0.16 & $1.07 \pm 0.35$ & 0.04 \\
\hline 8 & $0.66 \pm 0.28$ & 0.97 & & & & \\
\hline \multicolumn{7}{|c|}{$\mathrm{L}_{2}$ population } \\
\hline 1 & 0.96 & & $0.65 \pm 0.12$ & $5.53^{*}$ & 0.63 & \\
\hline 2 & $0.83 \pm 0.12$ & 1.67 & $0.44 \pm 0.07$ & $28.16^{* *}$ & $0.37 \pm 0.05$ & $58.74^{* *}$ \\
\hline 3 & $1.66 \pm 0.31$ & $7.52^{* *}$ & $0.31 \pm 0.07$ & $30.12^{* *}$ & $0.51 \pm 0.09$ & $15.12^{* *}$ \\
\hline 4 & $2.38 \pm 0.45$ & $22.38^{* *}$ & $0.41 \pm 0.08$ & $22.30^{* *}$ & $0.98 \pm 0.20$ & 0.01 \\
\hline 5 & $0.41 \pm 0.13$ & $8.45^{* *}$ & $0.39 \pm 0.18$ & $4.48^{*}$ & $0.16 \pm 0.06$ & $31.36^{* *}$ \\
\hline 6 & $1.07 \pm 0.61$ & 0.01 & & & & \\
\hline
\end{tabular}

$\dagger$ Asymptotic standard error.

${ }^{*} P<0.05,{ }^{* *} P<0.01$. 
Table 4 Average of fitness estimates over generations for the $\mathrm{Ba} /+$ heterozygote in $\mathrm{H}$ and $\mathrm{L}$ (high and low modifier effect) populations of Drosophila subobscura

\begin{tabular}{|c|c|c|c|c|c|c|}
\hline \multirow[b]{2}{*}{ Population } & \multicolumn{2}{|c|}{ Viability } & \multicolumn{2}{|c|}{ Fertility } & \multicolumn{2}{|c|}{ Total fitness } \\
\hline & $\hat{V} \pm \mathrm{SE} \dagger$ & Bootstrap interval $\ddagger$ & $\hat{F} \pm \mathrm{SE} \dagger$ & Bootstrap interval $\neq$ & $\hat{W} \pm \mathrm{SE} \dagger$ & Bootstrap interval \\
\hline $\mathrm{H}_{1}$ & $0.86 \pm 0.14$ & $\begin{array}{l}(0.64,1.14) \\
(0.55,1.23)\end{array}$ & $1.14 \pm 0.25$ & $\begin{array}{l}(0.71,1.61) \\
(0.63,1.85)\end{array}$ & $0.92 \pm 0.15$ & $\begin{array}{l}(0.68,1.25) \\
(0.63,1.43)\end{array}$ \\
\hline $\mathrm{H}_{2}$ & $1.37 \pm 0.14$ & $\begin{array}{l}(1.12,1.68)^{*} \\
(1.09,1.74)^{*}\end{array}$ & $0.75 \pm 0.11$ & $\begin{array}{l}(0.56,0.98)^{*} \\
(0.51,1.09)\end{array}$ & $0.99 \pm 0.11$ & $\begin{array}{l}(0.78,1.19) \\
(0.73,1.25)\end{array}$ \\
\hline $\mathrm{H}_{1}$ and $\mathrm{H}_{2}$ & $1.18 \pm 0.12$ & $\begin{array}{l}(0.98,1.40) \\
(0.94,1.51)\end{array}$ & $0.89 \pm 0.12$ & $\begin{array}{l}(0.68,1.16) \\
(0.64,1.23)\end{array}$ & $0.97 \pm 0.09$ & $\begin{array}{l}(0.80,1.13) \\
(0.76,1.19)\end{array}$ \\
\hline $\mathrm{L}_{1}$ & $1.20 \pm 0.17$ & $\begin{array}{c}(0.89,1.50) \\
(0.83,1.60)\end{array}$ & $0.63 \pm 0.13$ & $\begin{array}{l}(0.44,0.92)^{*} \\
(0.39,0.99)^{*}\end{array}$ & $0.75 \pm 0.13$ & $\begin{array}{l}(0.52,0.96)^{*} \\
(0.44,1.02)\end{array}$ \\
\hline $\mathrm{L}_{2}$ & $1.22 \pm 0.29$ & $\begin{array}{c}(0.78,1.78) \\
(0.66,1.92)\end{array}$ & $0.44 \pm 0.06$ & $\begin{array}{l}(0.37,0.56)^{*} \\
(0.34,0.58)^{*}\end{array}$ & $0.53 \pm 0.14$ & $\begin{array}{l}(0.34,0.82)^{*} \\
(0.27,0.86)^{*}\end{array}$ \\
\hline $\mathrm{L}_{1}$ and $\mathrm{L}_{2}$ & $1.21 \pm 0.15$ & $\begin{array}{l}(0.94,1.49) \\
(0.86,1.61)\end{array}$ & $0.55 \pm 0.08$ & $\begin{array}{l}(0.42,0.72)^{*} \\
(0.38,0.78)^{*}\end{array}$ & $0.66 \pm 0.10$ & $\begin{array}{c}(0.48,0.84)^{*} \\
(0.42,0.89)^{*}\end{array}$ \\
\hline
\end{tabular}

†Empirical standard error.

$\ddagger$ Upper and lower parentheses are 95 per cent and 99 per cent bootstrap confidence intervals, respectively.

${ }^{*}$ Statistical significance based on the bootstrap interval.

ten of 12 fertility estimates are statistically significant and in all these cases fertility is lower than unity. In egg-to-adult viability, some estimates are statistically significant but a difference between $\mathrm{H}$ and $\mathrm{L}$ cages is not observed.

Table 4 shows the averages of estimates of viability, fertility and total fitness for the $B a /+$ heterozygote over generations. The significance of these mean fitness values can be tested by means of the 95 and 99 per cent bootstrap confidence intervals estimated from the set of fitness values corresponding to the different generations of each experimental population. A clear effect of natural selection operating against the $B a /+$ heterozygote is observed in cages $\mathrm{L}$ for total fitness and fertility. In these cages, the averages of total fitness values of the $B a /+$ heterozygote are statistically significant and lower than one $(0.75 \pm 0.13$ and $0.53 \pm 0.14$ for $\mathrm{L}_{1}$ and $\mathrm{L}_{2}$, respectively), whereas in cages $\mathrm{H}$ the total fitness values are not significant and are very close to one. This selective effect appears to result mainly from the fertility component, as the averages of fertility estimates are statistically significant and lower than one in cages $L(0.63 \pm 0.13$ and $0.44 \pm 0.06$ for $L_{1}$ and $L_{2}$, respectively), whereas for cages $\mathrm{H}$ only the $\mathrm{H}_{1}$ population appears to present a weak selective effect $(0.75 \pm 0.11)$.

\section{Discussion}

The results presented here demonstrate that differences in modifier genetic background appear to result in important differences in the operation of selection on the $B a$ locus (Fig. 1; Table 4). In the experimental populations of high modifier background the total fitness of the $\mathrm{Ba} /+$ heterozygote was practically equal to that of the $+/+$ homozygote (average estimates were $0.92 \pm 0.15$ and $0.99 \pm 0.11$ in cages $\mathrm{H}_{1}$ and $\mathrm{H}_{2}$, respectively), whereas in cages of low modifier background a strong effect of selection against the $\mathrm{Ba} /+$ heterozygote was detected (averages of total fitness estimates were $0.75 \pm 0.13$ and $0.53 \pm 0.14$ in cages $L_{1}$ and $L_{2}$, respectively).

The fitness component responsible for this selection effect seems to be fertility as a strong fertility selection against the $B a /+$ heterozygote is detected in cages of low modifier background (averages of fertility estimates were $0.63 \pm 0.13$ and $0.44 \pm 0.06$ in cages $L_{1}$ and $L_{2}$, respectively). This is not an unusual result because there are many cases in the literature where fertility selection is an important component of total selection (Polivanov \& Anderson, 1969; Sved \& Ayala, 1970; Sved, 1971; Bundgaard \& Christiansen, 1972; Anderson et al., 1979). On the other hand, our experimental design for fitness estimation splits total fitness into a component of preadult survival or egg-to-adult viability and into an adult fitness component or fertility. The fertility component includes several late fitness components such as male mating success, female fecundity and probably also an adult survival component but under our experimental design it is not possible to state clearly on which of these adult fitness components 
the selection is acting on the $B a /+$ heterozygote. In addition, the population model for fitness estimation for lethal genes assumes sex-independent selection even though the adult fitness components such as sexual selection and fecundity will not be equal in the two sexes. Therefore, the obtained fertility estimates will be quite close to the averages of the selective values in the two sexes (Anderson, 1969).

The effect of genetic background on the fitness of genotypes at a given locus has been demonstrated in many instances (see for example Polivanov, 1964; Jones \& Yamazaki, 1974; McKenzie et al., 1982; McKenzie \& Purvis, 1984). Thus, this effect has been observed for morphological mutants, allozyme loci and others. In these cases, the genetic background produces changes in the fitness of genotypes at a given locus through fitness modifiers whose relationships with the main locus are unknown. The experiments reported here are substantially different from the classical experiments of genetic background because, in our case, we know that the studied modifiers are affecting the morphological expression of the $B a$ locus in such a way that the modifier background can be quantified in terms of phenotypic effects on the major locus. In this way, using a defined genetic background our experiment is mainly designed to evaluate the adaptive significance of the modifier variability, a type of genetic variability frequently occurring in natural populations (see Introduction) whose evolutionary meaning is not well known.

The selective effects generated by the polygenic modifiers on the $B a$ locus in the experimental populations can be directly related to the modifier genetic variability occurring in natural populations. This is possible because the modifier genetic background was accurately controlled in the foundation of the population cages and, in addition, because the distribution of modifier effects of $\mathrm{O}$ chromosomes in natural populations has been characterized (Alvarez et al., 1990). Thus, the difference in modifier genetic background between $\mathrm{H}$ and $\mathrm{L}$ cages corresponds to approximately two standard deviations in the distribution of modifier effect in natural populations (standard deviation of modifier effect was 2.51 for $\mathrm{O}_{\mathrm{ST}}$ chromosomes from natural populations, see Alvarez et al., 1990). This means that O chromosomes separated by approximately two standard deviations in their modifier effect in natural populations would be responsible for differences in selection coefficients of about $0.34 \pm 0.10 \mathrm{SE}$ in total selection and $0.45 \pm 0.08$ in fertility. These results demonstrate that the modifier gene polymorphism affecting the expression of the $B a$ mutant is produc- ing large selective effects on the major locus. Therefore, our results suggest that the contribution of minor loci to the adaptive evolutionary change might in some cases be comparable to that of major genes. Obviously, the generality of our findings cannot be determined until further studies quantify the selective effects of other modifier gene polymorphisms.

\section{Acknowledgements}

We thank Juán Baladrón for technical assistance, Mauro Santos for suggestions and comments on the experimental designs. The authors are also indebted to Timothy Prout for helpful comments on an early version of the manuscript.

\section{References}

ALvarez, G., ZAPATA, C. AND FONTDEvila, A. 1980. Modifier variability in a natural population of Drosophila subobscura. Genet. Acta Biol. Yugosl., 12, 81-89.

alvarez, G., MARTínez, P., ZaPATA, C., SANTOS, M. AND FONTDEVILA, A. 1981. Genetic analysis of modifier variability in Drosophila subobscura. Experientia, 37, 1150-1151.

ALVAREZ, G., SANTOS, M. AND ZAPATA, C. 1984. Frequencydependent selection arising from inappropriate fitness estimation. Evolution, 38, 696-699.

alvarez, G., martínez, P. AND Zapata, c. 1990. Genetic variation in a modifier system affecting the expression of Bare mutant of Drosophila subobscura. Heredity, 64, 55-66.

ANDERSON, w. w. 1969. Selection in experimental populations. I. Lethal genes. Genetics, 62, 653-672.

ANDERSON, W. W., LEVINE, L., OLVERA, O., POWELl, J. R., DE LA ROSA, M. E., SALCEDA, V. M., GASO, M. I. AND GUZMAN, J. 1979. Evidence for selection by male mating success in natural populations of Drosophila pseudoobscura. Proc. Natl. Acad. Sci. U.S.A., 76, 1519-1523.

BÖHM, I., PINSKER, W. AND SPERLICH, D. 1987. Cytogenetic mapping of marker genes on the chromosome elements $C$ and $E$ of Drosophila pseudoobscura and D. subobscura. Genetica, 75, 89-101.

BUNDGAARD, J. AND CHRISTIANSEN, F. B. 1972. Dynamics of polymorphisms. I. Selection components in an experimental population of Drosophila melanogaster. Genetics, 71, 439-460.

CONNOLLY, J. AND GLIDDON, C. 1984. On the estimation of viabilities in competition experiments. Heredity, 53, $527-543$.

EFRON, B. AND TIBSHIRANI, R. 1986. Bootstrap methods for standard errors, confidence intervals, and other measures of statistical accuracy. Statistical Sci., $\mathbf{1}$, $54-77$.

GeER, B. W. AND Laurie-Ahlberg, c. c. 1984. Genetic variation in the dietary sucrose modulation of enzyme 
activities in Drosophila melanogaster. Genet. Res., $\mathbf{4 3}$, 307-321.

JONES, J. S. AND YAMAZAKI, T. 1974. Genetic background and the fitness of allozymes. Genetics, 78, 1185-1189.

KOSKE, T. AND MAYNARD SMITH, J. 1954. Genetics and cytology of Drosophila subobscura. X. The fifth linkage group. J. Genet., 52, 521-541.

LAURIE-AHLBERG, C. C. 1985 . Genetic variation affecting the expression of enzyme-coding genes in Drosophila: An evolutionary perspective. In: Rattazzi, M. C., Scandalios, J. G. and Whitt, G. S. (eds) Isozymes: Current Topics in Biological and Medical Research, vol. 12. A. R. Liss, New York.

LAURIE-AHLBERG, C. C., Winton, A. N., CURTSINGER, J. W. AND EMIGH, T. H. 1982. Naturally occurring enzyme activity variation in Drosophila melanogaster. I. Sources of variation for 23 enzymes. Genetics, 102, 191-206.

LOUKAS, M., KRIMBAS, C. B., MAVRAGANI-TSIPIDOU, P. AND KASTRITSIS, C. D. 1979. Genetics of Drosophila subobscura populations. VIII. Allozyme loci and their chromosome maps. J. Hered., 70, 17-26.

McDONALD, J. F. AND AYALA, F. J. 1978a. Genetic and biochemical basis of enzyme activity variation in natural populations. I. Alcohol dehydrogenase in Drosophila melanogaster. Genetics, 89, 371-388.

MCDONALD, J. F. AND AYALA, F. J. 1978b. Gene regulation in adaptive evolution. Can. J. Genet. Cytol., 20, $159-175$.

McKeNZIE, J. A. AND PURVIs, A. 1984. Chromosomal localisation of fitness modifiers of diazinon resistance genotypes of Lucilia cuprina. Heredity, 53, 625-634.

McKeNZIE, J. A., WHITTEN, M. J. AND ADENA, M. A. 1982. The effect of genetic background on the fitness of diazinon resistance genotypes of the Australian sheep blowfly, Lucilia cuprina. Heredity, 49, 1-9.

MILKMAN, R. 1970. The genetic basis of natural variation.
X. Recurrence of cve polygenes. Genetics, 65, 289-303. POLIVANOV, s. 1964. Selection in experimental populations of Drosophila melanogaster with different genetic backgrounds. Genetics, 50, 81-100.

POLIVANOV, S. AND ANDERSON, w. w. 1969. Selection in experimental populations: II. Components of selection and their fluctuations in two populations of Drosophila melanogaster. Genetics, 63, 919-932.

PROUT, T. 1969. The estimation of fitness from population data. Genetics, 63, 949-957.

SPERLICH, D., FUERBACH-MRAVLAG, H., LANG, P., MICHAELIDIS, A. AND PENTZOS-DAPONTE, A. 1977. Genetic load and viability distribution in central and marginal populations of Drosophila subobscura. Genetics, 86, 835-848.

SVED, J. A. 1971. An estimate of heterosis in Drosophila melanogaster. Genet. Res., 18, 97-105.

SVED, J. A. AND AYALA, F. J. 1970. A population cage test for heterosis in Drosophila pseudoobscura. Genetics, 66, 97-113.

TEMPLETON, A. R. 1982. Adaptation and the integration of evolutionary forces. In: Milkman, R. (ed.) Perspectives on Evolution. Sinauer Associates, MA.

THODAY, J. M. AND THOMPSON, J. N., JR. 1984. Polygene polymorphism affecting wing vein formation in a natural population of Drosophila melanogaster. Heredity, $\mathbf{5 3}, 635-642$.

THOMPSON, J. N., JR AND SPIVEY, W. E. 1984. Organization of polygenic systems: Cell death modifiers from natural populations of Drosophila melanogaster. Genet. Res., 44, 261-269.

ZAPATA, C., ALVAREZ, G., DOSIL, M. AND FONTDEVIla, A. 1986. Genetic coadaptation in the chromosomal polymorphism of Drosophila subobscura II. Changes of gametic disequilibrium in experimental populations. Genetica, 71, 149-160. 